\title{
Determining Optimal Cell Density and Culture Medium Volume simultaneously in MTT Cell Proliferation Assay for Adherent Cancer Cell Lines
}

\author{
${ }^{1}$ Mohammadreza Moradi, ${ }^{2}$ Reza Solgi, ${ }^{3}$ Rezvan Najafi, ${ }^{4}$ Hamid Tanzadehpanah, ${ }^{* 5}$ Massoud Saidijam \\ $1,4,{ }^{* 5}$ Research Center for Molecular Medicine, Hamadan University of Medical Sciences, Hamadan, Iran. \\ ${ }^{2}$ Legal Medicine Research Center, Legal Medicine Organization of Iran, Hamadan, Iran, ${ }^{3}$ Department of \\ Molecular Medicine and Genetics, School of Medicine, Hamadan University of Medical Sciences, \\ Hamadan, Iran. \\ Email:sjam110@yahoo.com, Mobile:+989121324616
}

Received: $13^{\text {th }}$ February 2018, Accepted: $20^{\text {th }}$ February 2018, Published: $2^{\text {th }}$ February 2018

\begin{abstract}
:
Introduction: The MTT assay without optimization of the factors affecting cell metabolism can lead to false reports of the tested drugs. In this study, cell density and cell culture medium volume were optimized in a 96-well plate for Hepa1-6 cells as an adherent cell line. Methods: Hepa1-6 cells were seeded in the two different volumes, five cell densities, and three incubation times. After the incubation times, the optical densities were read at $570 \mathrm{~nm}$. The absorbances of wells in 100 and $150 \mu 1$ of cell culture medium volumes were compared and the optimum cell density was funded through the mean absorbance analysis of wells in the optimum volume. Results: The Independent sample t-test showed a significant difference ( $p$-value $=0.01$ ) between the absorbances of wells with 100 and 150 $\mu \mathrm{l}$ of volumes. Also, Pearson's correlation coefficient indicated that the optimum cell culture medium was $150 \mu \mathrm{l}$. The optimum cell density was 5000 cells/well obtained from the liner portion of the standard curve related to the optimum volume. Discussion: The optimal cell density and volume of cell culture medium for hepa1-6 cell line were found. In addition, a simple practical protocol was suggested to find the optimal factors mentioned for the adherent cell line in MTT assay.

Keywords: Cell Culture Techniques, Cell Line, Cell Proliferation, Cell Survival, Enzyme Linked Immunosorbent Assay, MTT Formazan, Methods.

\section{Introduction}

The drug-based investigations for cancer treatment are initiated via a quick screening of candidate antitumor agents against tumor cell lines in vitro. Tumor cell viability is determined following the exposure of the mentioned cell lines to some drugs for time duration. To detect viability of the living cells through mitochondrial dehydrogenase activities, MTT assay is as the best known enzymebased and most versatile quantitative method explained by Massom in 1983(Mosmann, 1983), which is also reliable for testing cytotoxicity and cell proliferation. It has been widely used with various modifications in recent years (Yang, et al., 2015). To
\end{abstract}

generate the reduced equivalents, such as NADH and NADPH, yellow MTT tetrazolium salt (3-(4, 5dimethylthiazolyl-2)-2, 5-diphenyltetrazolium bromide) is partly decreased by metabolically active cells with the help of dehydrogenase enzymes. Solubilization and quantification of the resultant intracellular purple formazan can be done through spectrophotometry.

However, false high or low cell counts may be calculated due to the significant modification of MTT-specific activity caused by some factors and various parameters affecting cellular metabolism. To prevent nutrient depletion, such parameters as cell density, fresh or old culture medium volumes, concentration, and exposure time should be incorporated into MTT. Thus, to minimize confusing effects, establishment of suitably controlling parameters for each cell line in the assay is of high importance (Sylvester, 2011). Among all, the two most important parameters are cell density and culture medium volume. If a high count of cells is seeded or less pure medium culture than proper is selected, a shortage of nutrients and non-drugrelated death will occur and a false report of the tested drug will be resulted.

To obtain a reliable result in MTT assay, any factors affecting the metabolic activities of cells for each cell line should be optimized. This is the first study to optimize MTT assay via a simultaneous focus on cell density and culture medium volume. According to the findings of this study, an easy and practical protocol could be proposed for determining the two mentioned parameters in the MTT cell proliferation assay for adherent cell lines. The result of this study can be applied to adherent cancer cell lines.

\section{Material and Methods Cell line}

Mouse hepatoma Hepa1-6 cells were purchased from the cell bank of Pasteur Institute, Tehran (Tehran, Iran) and cultured in a medium of DMEMhigh glucose (Gibco-BRL, USA) supplemented with $10 \%$ Fetus Bovine Serum (FBS) (Gibco-BRL, USA) 
and $1 \%$ Pen Strep (Bio Idea Group, Iran) at $37^{\circ} \mathrm{C}$ using $5 \% \mathrm{CO} 2$. When the cells were $80 \%$ confluent, they were harvested by $0.25 \%$ trypsin digestion (Gibco-BRL, USA).

\section{Cellular Dilution Preparation}

For harvesting cells from the cell culture flask, the medium was first removed and $3 \mathrm{ml}$ of sterile PBS was purred in the flask. Then, $200 \mu$ l of trypsin was added to the flask and incubated in $37^{\circ} \mathrm{C}$ for $5 \mathrm{~min}$. Afterwards, $2 \mathrm{ml}$ of the culture medium was added to $10 \%$ FBS to stop the digestion. After completing detachment of the cells, the suspension was collected from the flask and placed in a sterile tube and then centrifuged at $323 \mathrm{~g}$ for $10 \mathrm{~min}$. The digestion medium was removed and the cells were resuspended in $1 \mathrm{ml}$ of the culture medium. Following this, $10 \mu \mathrm{l}$ of the cell suspension was added to one side of a hemocytometer and the cells were counted. Cellular dilutions were made according to Table 1. To provide the cellular dilutions, at first, a primary cell suspension was prepared at a concentration of $1 \times 10^{6} \mathrm{cell} / \mathrm{ml}$ and this suspension was then used to prepare other dilutions. The primary cellular suspension volumes (cell suspension with $1 \times 10^{6}$ cell $/ \mathrm{ml}$ ) and the added culture medium were calculated in such a way that each $50 \mu \mathrm{l}$ from the suspension of tubes 1, 2, 3, 4, and 5 contained 1000 , 2000, 4000, 8000, and 16000 cells, respectively. It should be noted that the calculated amounts for the primary cell suspension and media culture volumes were 3 times more since three 96-well plates had been simultaneously seeded considering the 3 time periods of incubation (24, 48, and 72 hours).

\begin{tabular}{|l|r|r|r|r|r|}
\hline \multicolumn{7}{|c|}{ Table 1: Cellular Dilution Preparation } & \multicolumn{1}{|c|}{ Tubes } \\
\hline & \multicolumn{1}{|c|}{1} & 2 & 3 & 4 \\
\hline Cell count in each $50 \mu \mathrm{l}$ of the cellular dilution & 1000 & 2000 & 4000 & 8000 & 16000 \\
\hline cell count in the primary cell suspension $($ cell/ml) & $1 \times 10^{6}$ & $1 \times 10^{6}$ & $1 \times 10^{6}$ & $1 \times 10^{6}$ & $1 \times 10^{6}$ \\
\hline Volume of the primary cell suspension* $(\mu \mathrm{l})$ & 12.8 & 25.6 & 51.2 & 102.4 & 204.8 \\
\hline Volume of the media culture $(\mu \mathrm{l})$ & 2387.2 & 2374.4 & 2348.8 & 2297.6 & 2195.2 \\
\hline Total volume $(\mu \mathrm{l})$ & 2400 & 2400 & 2400 & 2400 & 2400 \\
\hline$*$ The amounts were calculated for seeding three 96-well plates $(24,48$, and 72 hours of incubation time).
\end{tabular}

\section{Cell Seeding:}

According to Figure 1, the wells in an empty 96-well plate were filled with 50 and $100 \mu$ of the culture medium (DMEM-high glucose supplemented with 10\% FBS and 1\% Pen Strep) in every other row.

Figure 1: Filling the empty 96-well plate with 50 and $100 \mu$ of the culture medium (DMEM-high glucose supplemented with $10 \%$ FBS and $1 \%$ Pen Strep). a: $50 \mu 1$ b: $100 \mu \mathrm{l}$

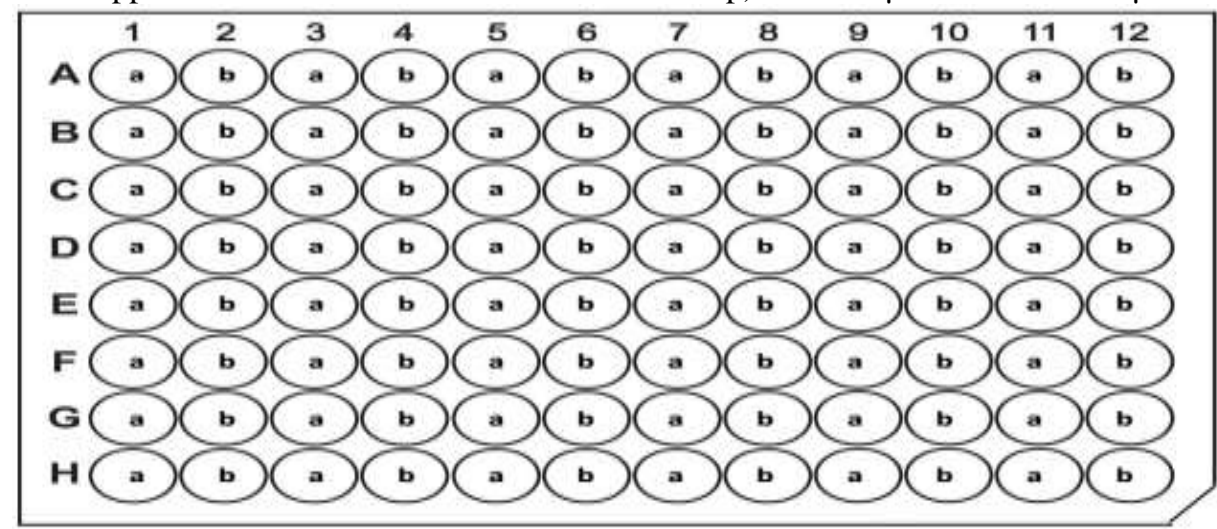

After pouring the culture medium in the wells, $50 \mu 1$ of each cell suspension (Table 1) was added to the wells in such a way that the vertical columns were the same in terms of the cell count (Figure 2).
Since the incubation times were considered to be 24 , 48, and 72 hours, three 96-wale plates were seeded according to the above instructions and the cell proliferation was assayed for each after the incubation. 
Figure 2: Addition of $50 \mu \mathrm{l}$ of the media culture to a and b as blank and then $50 \mu \mathrm{l}$ of the cellular dilutions to the pulled 96-well plate: 1000, 2000, 4000, 8000, and 16000 cell/well, respectively c, d, e, f, g

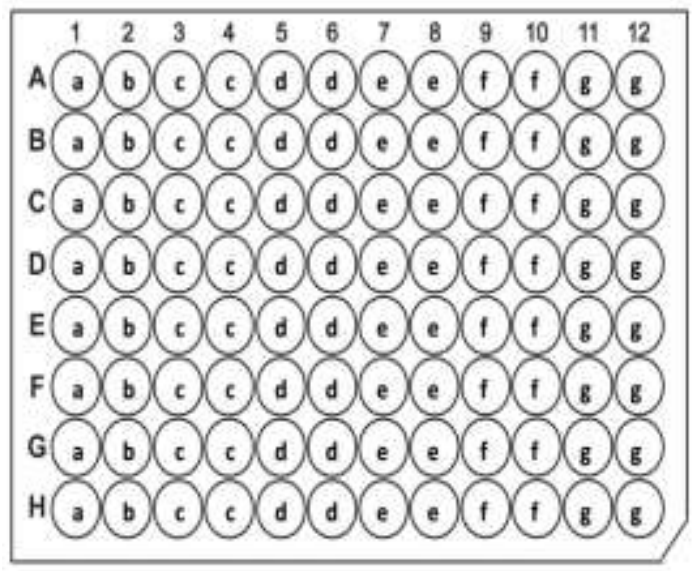

\section{Cell Proliferation Assay:}

Following the incubation time, $10 \mu \mathrm{l}$ of a $5 \mathrm{mg} / \mathrm{ml}$ stock solution of MTT (SIGMA-ALDRICH, USA) was added to each well and then, the plates were incubated at $37^{\circ} \mathrm{C}$ for the 4 hours again. The formazan crystals were solved by adding $100 \mu \mathrm{l}$ of DMSO solution (SIGMA-ALDRICH, USA). After mixing them thoroughly, the absorbance values were determined using Sunrise ${ }^{\mathrm{TM}}$ Microplate Reader (Tecan Group Ltd., Switzerland) at a wavelength of $570 \mathrm{~nm}$.

\section{Comparison of the Growth Rates between the Chosen Volumes:}

After reading the optical densities of the plates, the mean absorbances of the wells containing the selected volumes (100 and $150 \mu \mathrm{l}$ of the culture medium) were compared based on the different cell densities. Two curves were constructed by plotting the mean absorbance of the wells with the cell densities (1000, 2000, 4000, and 16000 cells/well) at three incubation times (24, 48, and 72 hours).

\section{Determining the Optimal Cell Culture Medium Volume:}

To determine the optimal cell culture medium volume, Pearson's correlation coefficient between the incubation times (24, 48 and 72 hour) as dependent variables and absorbencies as independent variables was determined. For each volume, one correlation coefficient was obtained and the two correlation coefficients were compared to determine the optimal cell culture medium volume.

\section{Determination of Optimal Cell Density:}

After finding the optimal cell culture medium volume, our analysis was continued on the data obtained from the optimal cell culture medium volume. A curve was constructed by plotting the dependent variables (cell density) on the $\mathrm{x}$-axis against the independent variables (optical density) on the y-axis. The plot of the data (absorbance against cell density) was provided as a line/line curve with a linear portion. The optimal number of the cells for the assay was within the linear portion of this curve.

\section{Statistical Analysis:}

The statistical analysis was performed by using SPSS version 16 . For the normal distribution analysis of the data, the Kolmogorov-Smirnov test was performed. Independent sample t-test and Levene's test were carried out to compare the mean absorbance and homogeneity of variances in the chosen volumes $(100$ and $150 \mu \mathrm{l})$. Pearson's correlation coefficient test was conducted to determine the optimal cell culture medium. The significance level was set at 0.05 .

\section{Results}

The result of Kolmogorov-Smirnov test showed that the mean absorption had a normal distribution ( $\mathrm{p}$ value $=0.132$ and 0.172 for 100 and $150 \mu 1$ respectively). The results of other statistical tests have given below.

\section{Determination of Optimal Cell Culture Medium Volume:}

The result of the independent t-test revealed a significant difference ( $p$-value $=0.01$ ) in the mean absorptions of the wells with $150 \mu 1(\mathrm{M}=0.299$, $\mathrm{SD}=0.168)$ and $100 \mu 1 \quad(\mathrm{M}=0.352, \mathrm{SD}=$ $0.187)$.Also, the result of levene's test represented a homogeneity of the variances amount at 150 and 100 $\mu 1$ (p-value=0.298). The result has shown in fig 3 . 
Figure 3: Comparison of the Mean Absorptions between the 100 and $150 \mu 1$ of media culture (p-value $<0.05$ )

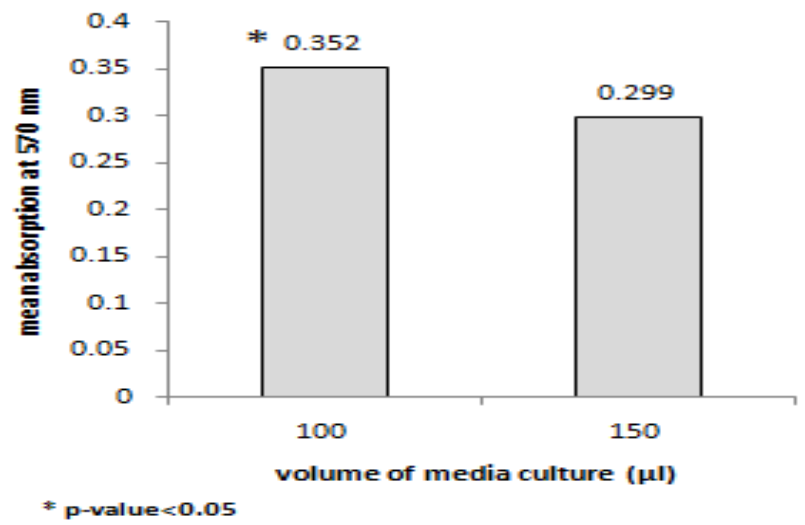

Pearson's correlation coefficient for the cell densities with the plate mean absorptions of 100 and $150 \mu 1$ of the media culture in each well were as follows, respectively: $\mathrm{r}=0.211$ and 0.244 (pvalues $=0.007$ ). As a result, a more strong positive correlation was found between the incubation times (24, 48 and 72 hour) and mean absorption in the wells with $150 \mu 1$ of the media culture in each well. Thus, it was concluded that the optimum volume of the media culture was $150 \mu 1$ in each well.

\section{Comparison of the Growth Rates between the Chosen Volumes:}

Figures $4 \mathrm{a}$ and $4 \mathrm{~b}$ display 2 curves with 5 series of data obtained from the cell densities. The results demonstrated that in the both volume of media culture $(100$ and150 $\mu \mathrm{l})$, the mean absorbance in 1000, 2000, and 4000 cell densities had a positive linear growth at all the incubation times after 48 hours, the mean absorption fell in 8000 and 16000 cell densities compared to the 24-hour incubation time

Figure 4: Comparison of the cell growth rates between the wells pulled with $100 \mu \mathrm{l}$ (a) and $150 \mu \mathrm{l}$ (b) of the culture medium (DMEM-high glucose supplemented with 10\% FBS and 1\% Pen Strep)
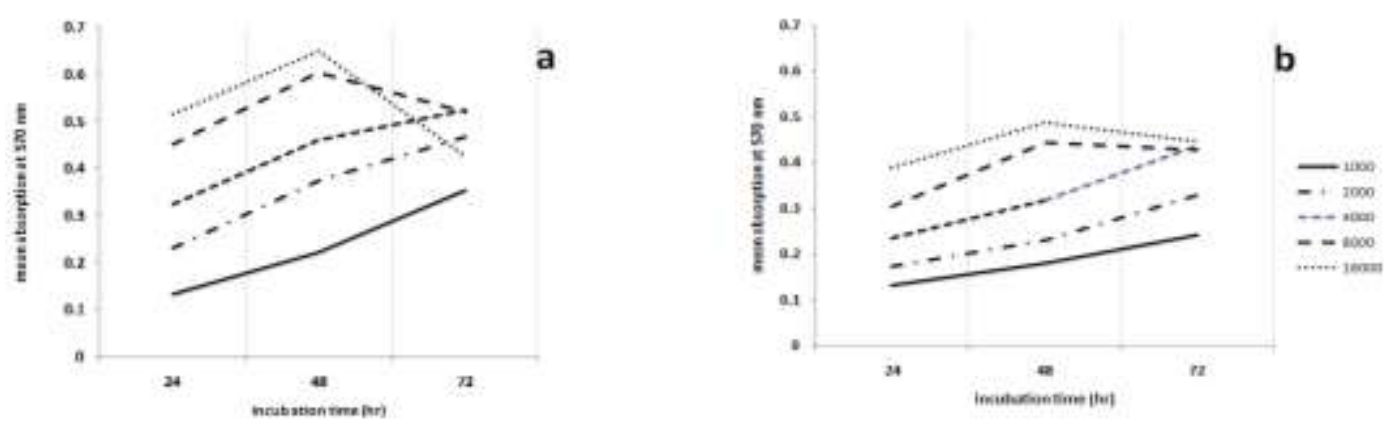

Also the comparison of $\mathrm{R}^{2}$ in the curves demonstrated that there is a substantially more correlation between mean absorptions and cell density in $150 \mu \mathrm{l}$ of media culture. The amounts of $\mathrm{R}^{2}$ for all curves have showed in table 2 .

Table 2: Comparison of the $\mathrm{R}^{2}$ and Growth Rates in Standard Curve between the Chosen Volumes

\begin{tabular}{|l|c|c|}
\hline Cell Density & \multicolumn{2}{|c|}{$\mathrm{R}^{2}$} \\
\hline 1000 & 100 & 0.993 \\
\hline 2000 & 0.9858 & 0.981 \\
\hline 4000 & 0.9856 & 0.9888 \\
\hline 8000 & 0.9596 & $0.665 *$ \\
\hline 16000 & $0.2017 * 3239 *$ \\
\hline$*$ negative growth rate after $48 \mathrm{hrs}$ & & $0.32 \%$ \\
\hline
\end{tabular}




\section{Determination of Optimal Cell Density:}

After finding the media culture optimums, the data analysis of the $150 \mu 1$ media culture in each well was done to determine the optimum cell density. Figure 5 portrays a curve constructed by plotting the cell density on the Xaxis against the optical density on the y-axis. For each cell density, the mean absorptions of 24, 48, and 72 hours of incubation were calculated. This curve had a linear portion between 4800 and 6200 cell/well, which represented the optimum cell density. It was concluded that the optimum cell density was approximately 5000 cell/well.

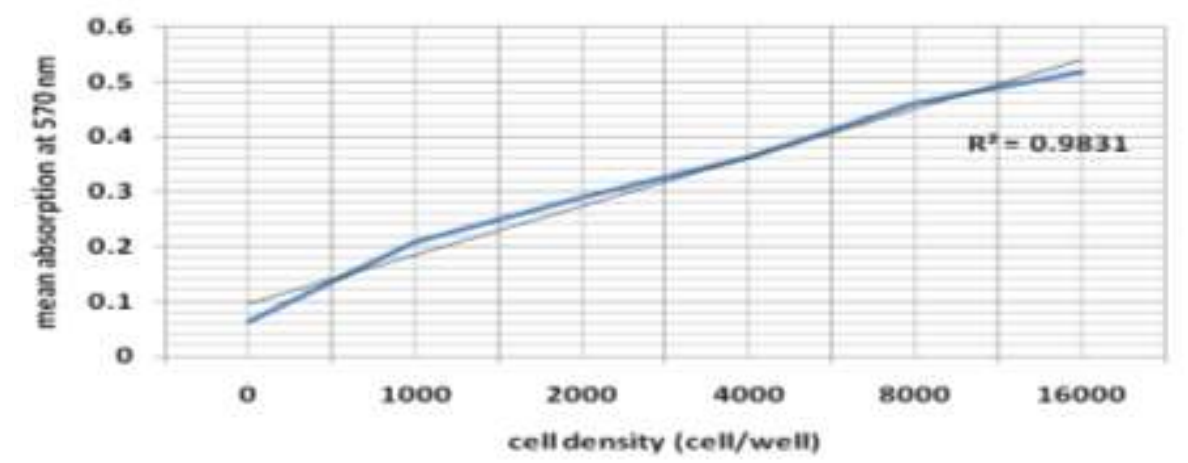

Figure 5: MTT Standard Curves for Hepa1-6 Cell Line. For each Cell Density, the Mean Absorptions of 24, 48, and 72 hours of Incubation Time were Calculated.

\section{Discussion}

The results of this study revealed two important points to be noted in MTT assay test. The first is a probable change in the logical and linear growths of cells in a high cell density. The cell growth may be decreased by increasing the cellular waste products or shortage of the required nutrients. In contrast, when the cell density is low, it may not be confluent. An optimal cell density, with which the cells can preserve a logical and linear growth rate during the incubation time must be determined. The second point is that in an inadequate medium cell culture volume, the amounts of cellular waste products will be increased sooner than the time it needs to reach an adequate volume. In this manner, the cell death will be induced because of highly dense waste products, thus leading to a non-drug-related death and a false report from the tested drug. According to the finding of this study, a practical process is suggested as a very simple protocol for optimizing the MTT cell proliferation assay in adherent cancer cell lines.

We believe that the results of this study can be only used for adherent cancer cell lines. As a result, the proposed practical protocol can be applied to the optimization of MTT assay test for adherent cancer cell lines. However, this weakness is traced back to the application of MTT assay test. If a cancer cell line is to be treated with a drug in a long incubation time (for example, for $72 \mathrm{hrs),} \mathrm{some} \mathrm{conditions} \mathrm{must}$ be provided for the cells not to die as a result of nutrient shortage until the end of the incubation time. As can be seen from Figure 4, deaths of the 8000 cells inoculated in the wells in 100 and $150 \mu \mathrm{l}$ cell culture medium are induced after 48 hours. Yet, it can be seen from Figure 4 that the growth in 4000 cell/ well in 100 and $150 \mu \mathrm{l}$ cell culture medium continues until 72 hours. This shows the importance of an optimum cell density. Also, according to Figure 5, the optimum cell density with a simultaneous positive liner growth and proper confluency is between 4000 cell/well and 8000 cell/well. This accurate optimum cell density can be determined as shown in Figure 4. This study resulted in the strong point that a simultaneous optimum cell density and optimum cell culture medium could be determined by the suggested simple practical protocol.

To measure cell viability, MTT assay has been widely used as reliable and convenient quantitative method though it has been reported as a less dependable assay compared to other tests like Crystal Violet Staining (CVS) (Śliwka, et al., 2016) and ATP assays in certain cases in few studies (Yang, et al., 2015). To detect the probable cytotoxic and mutagenic effects of some plant extracts, simultaneous MTT and Ames tests on bacterial, plant, and mammalian cells have been conducted in some researches (Eren, Özata, Konuk, Akyil, \& Liman, 2015). Anyhow, some problems of industrial factories can be fixed with the help of MTT assay. For instance, biofilm management is a most wellknown problem in the metalworking fluid systems. Biofilm is produced by gram-negative isolates, which have been recovered from field metalworking fluids and wild bacterial communities of different 
metabolic activities based on the types of fresh coolants. MTT assay can be applied to determine microorganisms' capacities of biofilm formation (Trafny, Lewandowski, Zawistowska-Marciniak, \& Stępińska, 2013).

An optimization of MTT curve must be done for each cell line since a great variability is resulted from different cellular metabolic activities. Also, an optimum condition is required during treatment when testing the agents' effects on viability and proliferation. MTT concentration and dose and time responses to maximum formazan production are of the parameters affecting the assay reliability (Carmichael, DeGraff, Gazdar, Minna, \& Mitchell, 1987; Sylvester, Birkenfeld, Hosick, \& Briski, 1994). Establishment of optimum concentrations, exposure times, and assay length that do not result in the nutrient depletion from the medium besides utilizing the initial cell inoculation densities are the other most critical conditions needed to be considered in each MTT assay performance (Vistica, et al., 1991). Few studies have been performed on the optimum conditions for MTT assay (Grela, Zabek, \& Grabowiecka, 2015) (Wang, Cheng, Wang, Wei, \& Wang, 2010) (Plumb, Milroy, \& Kaye, 1989). Nonetheless, this is the first study focused on culture medium volume and cell density simultaneously, thus suggesting a practically simple protocol to improve MTT assay. However, some articles dealing with MTT assay precision affected by cell density are mainly microbiological studies (Patel, Oudemans, Hillman, \& Kobayashi, 2013).

Based on the flowing steps it could be designed a simple and practical protocol to optimize two mentioned parameter in MTT assay test:

\section{A: Determination of Optimal Cell Culture Medium Volume:}

1. Three 96-well plates cell cultures were prepared for seeding cells at three different incubation times $(24,48$, and 72 hours).

2. Two different volumes of media culture were selected (100 and $150 \mu \mathrm{l})$. All the plate wells were filled according to Figure 1 . Note that $50 \mu 1$ of the media culture will be added to the cell suspensions.

3. A cell suspension from the intended adherent cancer cell line was prepared with a certain cell density $\left(1 \times 10^{6}\right.$ cells $\left./ \mathrm{ml}\right)$.

4. Five cell densities were selected (1000, 2000, 4000, 8000, and 16000 cells/well) and a serial dilution was made in 5 tubes as shown in Table 1.

5. All the wells were filled with $50 \mu 1$ of the 5 cell suspensions tubes according to Figure 2.
6. The plates were incubated and the absorbance values were read at the wavelength 570 $\mathrm{nm}$ by using an ELISA reader.

7. To find the optimum medium culture volume, the correlation coefficient between the mean absorptions and the two medium culture volumes were calculated using the statistical software. The higher correlation coefficient represented the optimum medium culture volume.

\section{B: Determination of Optimal Cell Density:}

After finding the optimum volume of the cell culture medium, the analysis was continued with the data related to that volume.

1. A curve of cell density (cell/well) on the Xaxis against the optical density on the y-axis was plotted.

2. The linear portion of the curve was determined.

3. The optimal cell density of the mentioned cell in the optimal cell culture medium was within the linear portion of the curve.

\section{Conclusion}

The first chain of the studies conducted on drug therapies for cancer treatment is based on MTT cell proliferation assay. Because of the different metabolic activities of the cells, there is a great variability and the MTT curve needs to be optimized for each cell. The 2 most important parameters that can affect on the metabolic activities and enhance the variability are cell density and culture medium volume. In this investigation, a simple and practical protocol was suggested for optimizing the MTT cell proliferation assay, which can be used for adherent cancer cell lines.

\section{Conflict of Interest}

The authors declared no conflicts of interest.

\section{Acknowledgment}

The authors thank the Hamadan University of Medical Sciences for financial support of this study. The study was funded Molecular medicine and genetics research center, Hamadan University of Medical Sciences (No. 9412257461).

\section{References}

Carmichael, J., DeGraff, W. G., Gazdar, A. F., Minna, J. D., \& Mitchell, J. B. (1987). Evaluation of a tetrazolium-based semiautomated colorimetric assay: assessment of chemosensitivity testing. Cancer Res, 47, 936-942.

Eren, Y., Özata, A., Konuk, M., Akyil, D., \& Liman, R. (2015). A mutagenicity and cytotoxicity study on Limonium effusum aqueous extracts by Allium, Ames and MTT tests. Cytology and Genetics, 49, 125-133. 
Grela, E., Zabek, A., \& Grabowiecka, A. (2015). Interferences in the Optimization of the MTT Assay for Viability Estimation of Proteus mirabilis. Avicenna J Med Biotechnol, 7, 159-167.

Mosmann, T. (1983). Rapid colorimetric assay for cellular growth and survival: application to proliferation and cytotoxicity assays. J Immunol Methods, 65, 55-63.

Patel, N., Oudemans, P. V., Hillman, B. I., \& Kobayashi, D. Y. (2013). Use of the tetrazolium salt MTT to measure cell viability effects of the bacterial antagonist Lysobacter enzymogenes on the filamentous fungus Cryphonectria parasitica. Antonie Van Leeuwenhoek, 103, 1271-1280.

Plumb, J. A., Milroy, R., \& Kaye, S. B. (1989). Effects of the pH Dependence of 3-(4,5Dimethylthiazol-2-yl)-2,5-diphenyltetrazolium

Bromide-Formazan Absorption on Chemosensitivity Determined by a Novel Tetrazolium-based Assay. Cancer Res, 49, 44354440.

Śliwka, L., Wiktorska, K., Suchocki, P., Milczarek, M., Mielczarek, S., Lubelska, K., Cierpiał, T., Łyżwa, P., Kiełbasiński, P., Jaromin, A., Flis, A., \& Chilmonczyk, Z. (2016). The Comparison of MTT and CVS Assays for the Assessment of Anticancer Agent Interactions. PLoS ONE, 11, e0155772.

Sylvester, P. W. (2011). Optimization of the tetrazolium dye (MTT) colorimetric assay for cellular growth and viability. Methods in molecular biology (Clifton, N.J.), 716, 157-168.

Sylvester, P. W., Birkenfeld, H. P., Hosick, H. L., \& Briski, K. P. (1994). Fatty acid modulation of epidermal growth factor-induced mouse mammary epithelial cell proliferation in vitro. Exp Cell Res, 214, 145-153.

Trafny, E. A., Lewandowski, R., ZawistowskaMarciniak, I., \& Stępińska, M. (2013). Use of MTT assay for determination of the biofilm formation capacity of microorganisms in metalworking fluids. World Journal of Microbiology and Biotechnology, 29, 1635-1643.

Vistica, D. T., Skehan, P., Scudiero, D., Monks, A., Pittman, A., \& Boyd, M. R. (1991). Tetrazoliumbased assays for cellular viability: a critical examination of selected parameters affecting formazan production. Cancer Res, 51, 2515-2520.

Wang, H., Cheng, H., Wang, F., Wei, D., \& Wang, X. (2010). An improved 3-(4,5-dimethylthiazol-2yl)-2,5-diphenyl tetrazolium bromide (MTT) reduction assay for evaluating the viability of Escherichia coli cells. Journal of Microbiological Methods, 82, 330-333.

Yang, Y., Lu, Y., Wu, Q.-Y., Hu, H.-Y., Chen, Y.H., \& Liu, W.-L. (2015). Evidence of ATP assay as an appropriate alternative of MTT assay for cytotoxicity of secondary effluents from WWTPs. Ecotoxicology and Environmental Safety, 122, 490496. 